\title{
Ferramenta de análise de riscos na concessão de crédito por cooperativas financeiras para pessoas jurídicas
}

\author{
Risk analysis tool for granting credit by financial cooperatives for legal entities
}

\begin{abstract}
Resumo
Este estudo objetiva elaborar uma ferramenta de análise com visão ampla dos riscos envolvidos em uma cooperativa financeira na concessão de crédito. Analisou-se os riscos na cooperativa afim de identificar as atuais ferramentas de análise de crédito; verificar a eficiência destas, as mutações do risco e seus impactos durante diferentes períodos. Operacionalizou-se entrevistas com gerentes, bem como um levantamento documental da carteira de crédito, que revelou que a falta de uma efetiva análise dos riscos na concessão de crédito interfere diretamente no resultado econômico da instituição, a qual representaria em média cinco milhões a mais entre 2010 e 2016 . Os achados demonstram que $26 \%$ das concessões no período analisado não foram recuperados. Conclui-se que a análise de crédito na cooperativa investigada apresenta limitações, principalmente quanto aos riscos não identificados previamente à concessão de crédito, portanto, desenvolveu-se um modelo genérico de avaliação ampla de riscos capaz de sanar as fragilidades encontradas.
\end{abstract}

Palavras-chave: riscos corporativos, análise de crédito, ferramenta de análise, instituições financeiras cooperativas.

\begin{abstract}
This study aims to elaborate an analysis tool with a broad view of the risks involved in a financial cooperative in granting of credit. The risks in cooperative were analyzed to identify current tools of credit analysis; to verify the efficiency of these, the risk mutations and their impacts during different periods. This research was applied with managers by an interview and was carried out a documentary survey of loan portfolio, which revealed that the lack of an effective credit risk analysis interferes directly with the institution's economic result, which would represent an average of five million more between 2010 and 2016 . The findings show that $26 \%$ of concessions in the analyzed period were not recovered. It is concluded that the analysis of credit in the cooperative investigated has limitations, mainly regarding the risks not identified before the granting of credit, therefore, a generic model of comprehensive risk assessment was developed, capable of remedying the frailties found.
\end{abstract}

Keywords: corporate risk, credit analysis, analysis tool, cooperative financial institutions.

Adailton Vieira ${ }^{\mathrm{I}}$, Marino Luiz Eyerkaufer ${ }^{\mathrm{II}}$, Rodrigo Rengel ${ }^{\mathrm{III}}$

${ }^{\mathrm{I}}$ Universidade do Estado de Santa Catarina (UDESC), adailton_pg@hotmail.com

${ }^{\text {II }}$ Universidade do Estado de Santa Catarina (UDESC), marino.luiz@udesc.br

III Universidade Federal de Santa Catarina (UFSC), rengel.rodrigo@hotmail.com 


\section{Introdução}

O país encontra-se em um cenário de retração econômica de longa duração e com elevados níveis de desemprego (Sicsú, 2018). Na qual as perspectivas mudam a cada instante e a cada movimento político, o que impossibilita previsões estáticas sobre um período de curto prazo.

A redução do Produto Interno Bruto (PIB) e o aumento de desemprego atingiu também as empresas. Paralelo a isso, o número de inadimplentes também aumentou se comparado a períodos anteriores (Sistema de Proteção de Crédito - SPC, 2016).

Mesmo diante do cenário exposto, não se pode perder de vista que toda instituição possui finalidade de agregar valor às partes envolvidas, seja financeiro ou não. A gestão de riscos corporativos tem a missão de identificar nas incertezas da organização, os riscos e oportunidades que podem surgir ou que surgem no dia a dia. Desta forma, estes podem representar oportunidades de adicionar valor ou até mesmo destruí-lo. Nesse aspecto, a análise de riscos financeiros é mais uma forma de solidificar os resultados e melhorar a segurança nas liberações de créditos.

Entre os vários riscos que podem interferir na árdua missão do gestor em agregar valor estão os riscos financeiros. Os quais podem impactar diretamente nos demais, destarte, devem ser tratados de forma singular.

Como evitar uma possível inadimplência ou impedir que o seu aumento interfira no seu resultado? Ou ainda como manter a margem de lucro em tempos de retração da economia? Essas são algumas das situações que a gestão de riscos, mais especificamente de riscos financeiros, tenta gerir de forma a evitar qualquer falha ou mutação fora de um desvio padrão aceitável.

Neste panorama, as instituições financeiras cooperativistas, precisam se alertar quanto às suas ferramentas de análise de risco. Da teoria de riscos corporativos, os riscos financeiros representam para as instituições financeiras uma ameaça à sua sobrevivência. Ao mesmo tempo que os riscos estratégicos, operacionais e perigos, precisam ser desvendados nas análises de concessão de crédito para Pessoas Jurídicas (PJ).

Devido ao cenário em que nos encontramos, a análise de crédito ficou mais criteriosa, de maneira a visar reduzir, mitigar ou até mesmo eliminar o risco de uma operação. Frente a isso, a atualização das ferramentas de análise de crédito, são fundamentais para evitar inadimplências futuras e garantir o recebimento do crédito liberado, conforme pactuado em contrato no momento da liberação.

Estudos na área de riscos corporativos são comuns na literatura (Pinto, 2012; Menezes, 2012; Etges \& Souza, 2015). Já estudos tratando especificamente os riscos financeiros para instituições de crédito são encontrados com pouca frequência. Pedote (2002) descreve os desafios da análise e gerenciamento de riscos com enfoque nos riscos operacionais da instituição financeira. Já Leite, Alves e Filho (2010) apresentam uma discussão em torno dos riscos operacionais em uma instituição financeira pública que atua no Brasil.

Diante do exposto, têm-se como objetivo elaborar uma ferramenta de análise com visão ampla dos riscos envolvidos em uma cooperativa financeira na concessão de crédito.

Para isto busca-se identificar a eficiência da análise de riscos na concessão de créditos para PJ, numa instituição financeira cooperativa; demonstrar as atuais ferramentas de análise de risco na concessão de créditos (adotadas pela instituição financeira cooperativa pesquisada); apresentar os dados da carteira do crédito concedido pela instituição financeira cooperativa e ainda os fatores da inadimplência; e comparar a mutação do nível de risco em períodos de crescimento da economia e de retração e qual seu impacto sobre a inadimplência e prejuízo. 
Justifica-se este estudo a partir das sugestões de pesquisas futuras de Molyneux (2018), o qual a partir de sua revisão da literatura apontou a necessidade de um índice de risco sistêmico, este apontou ainda que cada vez mais pesquisadores da área bancária utilizam-se de variáveis de riscos sistêmicos, deste modo, buscou-se agregar à literatura ao abranger cooperativas de crédito.

Surge assim a contribuição científica do presente estudo, ao trazer a discussão da análise de riscos, inicialmente na visão dos riscos financeiros, para a instituição financeira e depois, o conjunto dos riscos que devem ser considerados por meio das ferramentas de análise, para identificar os diversos riscos das PJ captadoras de recursos. Contribui-se ainda quanto à prática com o desenvolvimento de uma ferramenta de análise de crédito para avaliação de riscos corporativos dos tomadores de crédito, por conseguinte, agrega à sociedade na medida que se analisa os riscos dos credores, bem como devido ao fato de que os proprietários de cooperativas de crédito são os próprios cooperados.

\section{Fundamentação Teórica}

\subsection{Riscos corporativos}

A palavra risco significa que algo pode não sair como o planejado, significa que algo é arriscado ou arriscar-se. Mas, atualmente essa palavra leva a um entendimento muito mais amplo, envolve uma medida quantitativa e qualitativa de incerteza em torno de qualquer atividade realizada seja na vida pessoal, profissional ou até mesmo em corporações (IBGC, 2007).

Mas, não necessariamente pode ser uma situação negativa. Em termos financeiros pode se dizer que a relação risco versus retorno tem correlação direta. Quanto maior o risco, maior pode ser o retorno. Esse dilema aplica-se também ao cotidiano empresarial à medida que se aumenta o retorno e agrega-se um valor maior que o esperado em torno da organização (IBGC, 2007).

A definição de gestão de risco corporativo pode ser traduzida como um processo multinível, contínuo e que flui por meio da organização. Conduzido para ser aplicado as estratégias da organização, de modo a identificar eventos em potencial, que podem representar risco e oportunidades, bem como tratá-los de acordo com o apetite de riscos disposto a correr (COSO, 2007).

Os objetivos da gestão de riscos corporativos são: alinhar os riscos que a empresa está disposta a correr com as estratégias adotadas para cada objetivo; reagir aos riscos da melhor forma possível a fim de mitigar, evitar, eliminar ou aceitar os riscos; reduzir surpresas ou prejuízos operacionais; identificar riscos múltiplos e sistêmicos; aproveitar oportunidades com proatividade; e otimizar o capital por meio de uma análise eficaz da sua necessidade, origem e destino (COSO, 2007).

O gerenciamento de risco deve garantir que as estratégias e apetite a risco definido pelo conselho de administração para os diversos níveis de risco da organização estejam em linha com os objetivos estratégicos da mesma, e sejam elaborados por meio de processos estruturados $\left(B_{3}, 2015\right)$.

Existe correlação direta entre os objetivos que se pretende alcançar com os componentes da gestão de riscos corporativos. Que representam aquilo que é necessário para seu alcance. Estes objetivos se subdividem em quatro categorias: estratégicos, operacionais, comunicação e conformidade (COSO, 2007). Na mesma linha o IBGC (2007) categoriza os riscos como estratégicos, operacionais e financeiros, ou ainda estratégicos, operacionais, financeiros e perigos (Ferma, 2003).

A respeito da estrutura de governança corporativa e gestão de riscos, Coimbra (2011) relata os prejuízos que os investidores e acionistas sofreram, os quais fizeram com que os órgãos que regulam o sistema financeiro adotassem uma série de medidas para aumentar as exigências legais no sentido 
de que as empresas empreguem mecanismos mais rígidos de governança corporativa e de gestão de riscos.

Conclui que as questões ambientais, ou seja, econômicos, políticos, legais, sociais, tecnológicos, da ação de concorrentes e de clientes, bem como a partir da tomada de decisões estratégicas são originadas por meio dos riscos estratégicos, riscos políticos e de reputação. Como demonstrado por Jacomossi et al. (2016) ao demonstrar as diferenças de riscos estratégicos entre bancos estatais e privados.

\subsection{Gestão de crédito}

A intermediação financeira gerou uma evolução na sociedade na era do escambo, fortaleceu a economia e ampliou a produção e demanda por bens e serviços. Além de dar a opção de escolha e comparabilidade aos produtos desejados pelo cidadão (Silva, 2008).

A necessidade expandiu-se com o aumento da produção de bens duráveis como veículos e eletrodomésticos. Em tempos de prosperidade é importante a facilidade de modalidades e acesso ao crédito (Tavares, 1988).

Nesse sentido, ressalta-se a principal função das instituições é a intermediação financeira, que em termos contábeis, nada mais é do que uma operação passiva no momento de captar dinheiro junto a seus clientes, e ativa no momento de liberação de empréstimos e financiamentos (Silva, 2008).

Criou-se então a central de riscos foi por meio da resolução $\mathrm{n}^{\circ} \mathbf{2 . 3 9 0}$ de 22 de maio de 1997 com o intuito de proteger e regulamentar o sistema financeiro, bem como garantir que o Bacen tenha acesso a quem empresta, como empresta e para quem empresta, a qualidade dos tomadores e do mercado de crédito de uma forma geral (Silva, 2008).

Em finanças entende-se o risco como instabilidades no retorno dos investimentos muitas vezes usa-se as palavras risco e incertezas indistintamente. Porém, incertezas seriam situações que não se pode prever, enquanto o risco é possível ser calculado (Silva, 2008).

A cessão de crédito gera por si só uma expectativa de recebimento do capital cedido. Por isso é importante reconhecer que em qualquer operação deve existir a noção de risco. Cabe ao cedente a decisão de cedê-lo ou não (Schrickel, 1994). Em virtude desta necessidade de decisões assertivas, pesquisas anteriores analisaram métodos para concessão de crédito com minimização da inadimplência (ver Scarpel \& Milioni, 2002; Sá et al., 2018).

Como o sistema financeiro é composto por tomadores de recursos (empréstimos) e por poupadores (investimentos), as taxas cobradas em empréstimos visam cobrir a remuneração dos investimentos já com a adição do ganho desejado pela instituição, conhecido como SPRED (em inglês significa propagação). Inclui-se ainda o risco que a entidade se propôs a correr na intermediação (Silva, 2008).

A principal forma de cálculo e mensuração de riscos é a análise de crédito, logo, este torna-se o seu objetivo dentro da instituição. Suas recomendações e ponderações devem estabelecer parâmetros para as particularidades da operação (Schrickel, 1994).

Sempre que uma instituição financeira realiza um empréstimo, esta assume o risco de não receber esse valor. Denota-se que o não pagamento dessa operação pode ocorrer por vários motivos. Contudo, as instituições devem tentar reduzir esse risco de várias formas, seja por garantias ou por análise criteriosa das liberações, bem como pela boa qualidade de carteira de clientes (Silva, 2008). 
Risco de crédito se resume no não pagamento de empréstimos por parte de clientes, o que gera prejuízos devido a perda do ativo emprestado, custos com recuperação deste crédito ou redução de ganhos devido a vantagens concedidas nas operações (B3, 2015).

É importante as instituições terem em sua carteira uma cobrança de taxas suficientes para pagar a remuneração de investimento de forma satisfatória aos investidores e aos acionistas. Caso o risco de mercado não seja observado de forma correta, a instituição pode ter grandes prejuízos ou perdas de investidores. (Silva, 2008).

Önder e Ergin (2012) relatam ainda que as empresas que possuem uma gestão de riscos e mantém por período maior os profissionais responsáveis por essa gestão, tendem a melhorar sua gestão e evoluir seu padrão de operação. Entretanto, Franco (2018) entende que as cooperativas ainda necessitam reforçar a gestão do crédito.

\subsection{Instituições financeiras cooperativas}

O cooperativismo surgiu nos primórdios da humanidade, época em que os homens primitivos se uniam para caçar grandes animais. Evoluiu e tornou-se uma grande tendência mundial. Passou a incorporar em várias áreas como crédito, habitacional, de produção, de educação, do agronegócio e de transporte (Heinzelmann \& Souza, 2009).

As instituições financeiras cooperativas possuem um objetivo social de distribuição de oportunidade. A carta magna descreve quais os objetivos do estado perante a população, objetivos esses que são similares ao cooperativismo (Meinen \& Port, 2012). De acordo com Bonizio e Silva (2018), tais instituições possuem vantagens aos seus associados, devido as taxas vantajosas quando comparadas com bancos comerciais.

O cooperativismo tem por objetivo a produção de riqueza e, por meio de um conceito de união e fraternidade proporcionar que todos da sociedade em que estão inclusos tenham acesso a mesma oportunidade de forma justa. No cooperativismo, a riqueza gerada em determinado local continua no mesmo local, proporciona-se assim um crescimento sustentável (Pinho \& Palhares, 2010; Meinen \& Port, 2012), por meio da distribuição dos resultados aos cooperados associados.

Seu funcionamento é regido pelos valores de solidariedade, liberdade, democracia, equidade, igualdade e os princípios do cooperativismo de crédito moderno foram elaborados em Rochdale na Inglaterra, durante a revolução industrial e após pequenas adequações a realidade atual permanecem com o mesmo intuito. Nos momentos de crise, o cooperativismo cresce sempre pautado em seus princípios e valores (Pinho; Palhares, 2010).

As cooperativas de crédito estão amparadas pela Lei 5.764/71, a qual apresenta as regras para seu funcionamento, tratamento fiscal e incentivo a população como forma de disponibilizar crédito de uma forma mais barata e justa (Meinen; Port, 2012).

Devido ao fato de as cooperativas não terem objetivo de gerar lucro, existe sempre ativa entre os envolvidos (colaboradores, cooperados, diretores, conselhos) uma discussão de como trabalhar quanto a questão de resultados no final dos exercícios. Porém, já ficou claro que mesmo instituições sem fins lucrativos o resultado positivo final deve ser alcançado devido ao risco envolvido (Meinen \& Port, 2012). Decorre assim a importância das cooperativas efetuarem uma boa análise de riscos para não comprometer os resultados com a não efetivação de créditos concedidos.

\section{Procedimentos Metodológicos}

Trata-se de um estudo descritivo, que fez uso dos métodos de pesquisa (i) documental, na qual se fez um levantamento das ferramentas de análise de crédito utilizadas na cooperativa; 
observou-se em analises de crédito já realizado e pesquisa no manual de crédito, política de crédito da instituição financeira estudada e por meio de entrevista com o analista de crédito; e (ii) participativa, com abordagem qualitativa dos dados, por meio de levantamento de dados do desempenho do crediário; utilizou-se dos relatórios internos da instituição e entrevista aos gerentes de relacionamento responsáveis pela gestão da carteira de crédito em que os inadimplentes se encontram para o desenvolvimento da ferramenta de análise de risco.

Foram entrevistados 15 gerentes de relacionamento na área de atuação no Vale do Itajaí/SC. Durante a entrevista abordou-se todos os contratos inadimplentes, os motivos alegados pelos gestores das empresas para a ocorrência do não pagamento. Optou-se por esta região devido a acessibilidade dos dados e conforme Santos et al. (2018) ao destacarem que a maioria das cooperativas de crédito que obtiveram $100 \%$ de eficiência em seu estudo e que não gerenciaram seus resultados, encontram-se no Estado de Santa Catarina.

Por fim, executou-se a construção de uma proposta de ferramenta de análise de crédito ampla que contempla as ferramentas já utilizadas, e incorpora dados coletados na revisão bibliográfica, com o intuito de criar uma análise mais qualificada dos tomadores de crédito. A partir dos modelos de Ferma (2003), COSO (2007), IBGC (2007) e ainda B3 (2015), sobre a gestão dos riscos corporativos e suas subclasses somado as respostas dos gerentes de relacionamento para elaborar um questionário quanto aos riscos operacionais, estratégicos, financeiros e perigos e chegar a uma classificação de preparo da gestão. Para agregar quanto ao aspecto financeiro e grau de solvência da empresa, utilizou-se o termômetro de insolvência de Kanitz (1974), que segundo Santos (2012), teve o maior índice de acerto entre os vários métodos testados (acerto de 88\%). Para a pontuação final, e análise do risco, considerou-se os riscos que a instituição está disposta a correr segundo seu manual e política de crédito.

\section{Análise dos Dados}

A instituição financeira analisada possui uma carteira de clientes em torno de 1.400 cooperados PJ, número que simboliza $18 \%$ da sua carteira geral de clientes. Sua carteira de crédito em posse de PJ é pouco mais de R\$ 175 milhões, o que representa 69\% de sua carteira total.

Para saber aonde se quer chegar é fundamental conhecer o ponto de partida, o caminho e os obstáculos que podem existir. Muitas vezes é impossível prever os eventos futuros, mas por meio de uma análise de um determinado histórico é possível chegar a uma previsão.

O mesmo acontece na análise e liberação de crédito, na qual constantemente tem-se que acompanhar o desenvolvimento e manutenção da carteira, além de observar os possíveis motivos pelos quais o tomador deixou de honrar com os pagamentos acordados na liberação do recurso. A Tabela 1 apresenta a evolução da inadimplência na cooperativa nos últimos anos.

Tabela 1: Carteira de crédito com sua evolução e inadimplência.

\begin{tabular}{l|c|r|r|r|r|r|r}
\multicolumn{1}{c|}{ Período } & $\mathbf{2 0 1 0}$ & \multicolumn{1}{c|}{$\mathbf{2 0 1 1}$} & $\mathbf{2 0 1 2}$ & \multicolumn{1}{c|}{2013} & $\mathbf{2 0 1 4}$ & $\mathbf{2 0 1 5}$ & $\mathbf{2 0 1 6}$ \\
\hline $\begin{array}{l}\text { Carteira crédito em milhões } \\
\text { de R\$ }\end{array}$ & 108,8 & 106,5 & 133,5 & 162,5 & 205,8 & 245,6 & 249,7 \\
\hline Evolução crédito & - & $-1,71 \%$ & $20 \%$ & $18 \%$ & $21 \%$ & $16 \%$ & $1,67 \%$ \\
\hline Inadimplência & $1,7 \%$ & $4 \%$ & $4,4 \%$ & $4,9 \%$ & $3,4 \%$ & $4,4 \%$ & $4,9 \%$ \\
\hline
\end{tabular}

Fonte: Dados da pesquisa

Na Tabela 1 demonstra-se a evolução da carteira de crédito do período de 2010 a 2016, bem como a inadimplência anual de cada período. Nela é possível observar uma evolução média próxima a 14,66\%, com exceção ao ano de 2011, no qual a carteira de crédito teve uma redução de $1,71 \%$ o que 
69 | Ferramenta de análise de riscos na concessão...

ocasionou a diminuição da média. Caso descontarmos 2011, essa média sobe para $18,75 \%$ ao ano, principalmente devido ao ano de 2014 com uma evolução foi de $21 \%$.

A Tabela 2 tem por finalidade evidenciar quanto da carteira total é composta por pessoa jurídica e sua representatividade total dentro da carteira de crédito da instituição.

Tabela 2: Composição de crédito da carteira.

\begin{tabular}{l|c|c|c|c|c|c|c}
\hline \multicolumn{1}{c|}{ Período } & $\mathbf{2 0 1 0}$ & $\mathbf{2 0 1 1}$ & $\mathbf{2 0 1 2}$ & $\mathbf{2 0 1 3}$ & $\mathbf{2 0 1 4}$ & $\mathbf{2 0 1 5}$ & $\mathbf{2 0 1 6}$ \\
\hline $\begin{array}{l}\text { Carteira crédito em milhões de } \\
\text { R\$ }\end{array}$ & 108,8 & 106,5 & 133,5 & 162,5 & 205,8 & $\mathbf{2 4 5 , 6}$ & 249,7 \\
\hline $\begin{array}{l}\text { Pessoa Jurídica em milhões de } \\
\text { R\$ }\end{array}$ & 53,3 & 54,5 & 82.4 & 105,7 & 137.2 & 169.2 & 171.5 \\
\hline Pessoa Jurídica em \% & $49 \%$ & $51 \%$ & $62 \%$ & $65 \%$ & $67 \%$ & $69 \%$ & $69 \%$ \\
\hline
\end{tabular}

Fonte: Dados da pesquisa

Gradativamente a carteira de crédito da pessoa jurídica assumiu papel de destaque ao chegar próximo a 70\% em 2015. Porém, o planejamento estratégico da instituição determina que o máximo a ser liberado para pessoas jurídicas é de $60 \%$, fato este que fez com que a instituição voltasse seu olhar para a pessoa física.

Assim como a carteira de crédito de uma forma geral teve um crescimento expressivo de 2010 a 2015, a carteira PJ em específico também teve seu crescimento destacado. Esta cresceu no período $217 \%$ enquanto a carteira geral cresceu $125 \%$. Em representatividade cresceu $20 \%$ no mesmo período.

Para poder descobrir os motivos da inadimplência das PJ questionou-se os gerentes de relacionamento da carteira sobre quais os motivos que levam as empresas à incapacidade de liquidação da dívida conforme acordado em contrato. Esse questionamento foi aplicado via telefone aos 15 gerentes de relacionamento que atuam na região do Vale do Itajaí/SC e abrangeram a todos os devedores que constam no sistema da instituição do período de 2010 a 2016 as respostas dadas pelos gestores (Tabela 3).

Tabela 3: Causas da inadimplência dos cooperados pessoa jurídica

\begin{tabular}{l|c}
\hline \multicolumn{1}{c|}{ Descrição } & Incidência \\
\hline Concentração do faturamento em poucos clientes & $\mathbf{2 4} \%$ \\
\hline Entidade pública como principal cliente & $\mathbf{2 2} \%$ \\
\hline Golpe/fraude & $9 \%$ \\
\hline Ausência de acompanhamento da economia (crise) & $\mathbf{1 5 \%}$ \\
\hline Aumento indiscriminado de endividamento & $\mathbf{2 3} \%$ \\
\hline Problemas familiares & $\mathbf{1} \%$ \\
\hline Ausência de estudo de viabilidade & $5 \%$ \\
\hline Desastres naturais & $\mathbf{2} \%$ \\
\hline
\end{tabular}

Fonte: Dados da pesquisa

A Tabela 3 demonstra os principais eventos, que segundo os gestores das empresas inadimplentes, contribuíram para o não cumprimento do acordado em contrato. Essas informações foram coletadas por meio de entrevistas aos gerentes responsáveis de cada contrato inadimplente. A amostra contempla o período de 2010 a 2016.

Com base em COSO (2007) o $1^{\circ}, 2^{\circ}$ e penúltimo item demonstram falha na gestão dos riscos estratégicos. Já o $3^{\circ}$ e o $6^{\circ}$ item demonstram falha no gerenciamento dos riscos operacionais segundo 
IBGC (2007). Enquanto o $4^{\circ}$ e o $5^{\circ}$ item são falhas na gestão dos riscos financeiros segundo a $\mathrm{B}_{3}$ (2015). Já segundo Ferma (2003) o último item representa os perigos a que as organizações estão expostas.

\subsection{Mutação do nível de risco em períodos de crescimento da economia e de retração e seu impacto na inadimplência e prejuízo}

Ao mudar sua estratégia e passar a trabalhar com intensidade as liberações de crédito para pessoas jurídicas, a inadimplência começou a surgir de uma forma diferente do que a instituição estava acostumada. Passou-se então a provisionar maiores montantes para crédito de liquidação duvidosa.

A estratégia obrigou a instituição a adaptar-se durante o processo em desenvolvimento e exigiu novos conhecimentos dos profissionais envolvidos na liberação análise e gestão do crédito. Durante o período de 2010 a 2015 o Rating sofreu várias mutações dentro de cada ano e entre um ano e outro.

Demonstra-se pela Tabela 4 a flutuação do risco estabelecido por meio do Rating de crédito conforme demanda a resolução do Banco Central do Brasil 2682/99 que leva em consideração apenas as flutuações de riscos das PJ bem como sua participação sobre o provisionamento total.

Tabela 4: Flutuação de provisionamento de crédito de liquidação duvidosa

\begin{tabular}{c|c|c|c|c|c|c|c}
\hline Rating & $\mathbf{2 0 1 0}$ & $\mathbf{2 0 1 1}$ & $\mathbf{2 0 1 2}$ & $\mathbf{2 0 1 3}$ & $\mathbf{2 0 1 4}$ & $\mathbf{2 0 1 5}$ & $\mathbf{2 0 1 6}$ \\
\hline A & $11,00 \%$ & $9,52 \%$ & $4,44 \%$ & $4,02 \%$ & $5,57 \%$ & $12,01 \%$ & $12,33 \%$ \\
\hline B & $15,69 \%$ & $11,47 \%$ & $4,12 \%$ & $4,29 \%$ & $5,51 \%$ & $7,96 \%$ & $6,55 \%$ \\
\hline C & $3,27 \%$ & $1,81 \%$ & $2,65 \%$ & $4,47 \%$ & $4,60 \%$ & $5,78 \%$ & $9,61 \%$ \\
\hline D & $8,19 \%$ & $13,32 \%$ & $1,91 \%$ & $1,46 \%$ & $1,55 \%$ & $1,53 \%$ & $0,45 \%$ \\
\hline E & $47,02 \%$ & $3,47 \%$ & $4,00 \%$ & $3,59 \%$ & $8,89 \%$ & $18,21 \%$ & $5,69 \%$ \\
\hline F & $2,32 \%$ & $2,76 \%$ & $4,35 \%$ & $10,86 \%$ & $12,94 \%$ & $19,36 \%$ & $4,74 \%$ \\
\hline G & $5,37 \%$ & $1,27 \%$ & $7,09 \%$ & $0,47 \%$ & $0,01 \%$ & $3,65 \%$ & $7,45 \%$ \\
\hline H & $7,14 \%$ & $56,38 \%$ & $71,44 \%$ & $70,84 \%$ & $60,93 \%$ & $31,50 \%$ & $53,20 \%$ \\
\hline TOTAL & & & & & & & \\
PJ & $63,89 \%$ & $48,59 \%$ & $73,48 \%$ & $74,70 \%$ & $73,17 \%$ & $72,61 \%$ & $66,82 \%$ \\
\hline PIB & $7,50 \%$ & $3,90 \%$ & $0,90 \%$ & $2,30 \%$ & $0,10 \%$ & $-3,80 \%$ & $-0,50 \%$ \\
\hline
\end{tabular}

Fonte: Dados da pesquisa

É possível observar que após redução do PIB o provisionamento de crédito de liquidação duvidosa aumentou significativamente. A participação da pessoa jurídica sobre o provisionamento total manteve-se acima de $70 \%$ a partir de 2012, ano em que foi registrado o início de retração da economia.

A retração da economia refletiu o impacto que a ausência de gestão de riscos corporativos fez nas empresas inadimplentes, durante a mesma entrevista utilizada para a coleta de dados da Tabela 6 , perguntou-se o que na visão deles fez com que as empresas adimplentes com a economia em alta se mantivessem na situação. A resposta foi preparo, organização, planejamento e conhecimento.

Na Tabela 5 nota-se claramente que o aumento da inadimplência gerou um provisionamento superior na carteira da pessoa jurídica a partir do ano de 2012, bem como um prejuízo maior que no ano de 2010, o qual não existia. 
71 | Ferramenta de análise de riscos na concessão...

Tabela 5 - Histórico de sobras, provisionamento e prejuízo da pessoa jurídica

\begin{tabular}{l|c|c|c|c|c|c|c}
\hline Descrição & $\mathbf{2 0 1 0}$ & $\mathbf{2 0 1 1}$ & $\mathbf{2 0 1 2}$ & $\mathbf{2 0 1 3}$ & $\mathbf{2 0 1 4}$ & $\mathbf{2 0 1 5}$ & $\mathbf{2 0 1 6}$ \\
\hline \multicolumn{1}{c}{ Sobras } & $\begin{array}{c}4,7 \\
\text { Milhões }\end{array}$ & $\begin{array}{c}4,1 \\
\text { Milhões }\end{array}$ & $\begin{array}{c}5,4 \\
\text { Milhões }\end{array}$ & $\begin{array}{c}4,3 \\
\text { Milhões }\end{array}$ & $\begin{array}{c}3,9 \\
\text { Milhões }\end{array}$ & $\begin{array}{c}7,4 \\
\text { Milhões }\end{array}$ & $\begin{array}{c}11 \\
\text { Milhões }\end{array}$ \\
\hline $\begin{array}{l}\text { Provisão } \\
\text { PJ }\end{array}$ & $\begin{array}{c}1,7 \\
\text { Milhões }\end{array}$ & $\begin{array}{c}\mathbf{1}, 6 \\
\text { Milhões }\end{array}$ & $\begin{array}{c}5,3 \\
\text { Milhões }\end{array}$ & $\begin{array}{c}6,9 \\
\text { Milhões }\end{array}$ & $\begin{array}{c}6,8 \\
\text { Milhões }\end{array}$ & $\begin{array}{c}4,5 \\
\text { Milhões }\end{array}$ & $\begin{array}{c}4,6 \\
\text { Milhões }\end{array}$ \\
\hline $\begin{array}{l}\text { Prejuízo } \\
\text { PJ }\end{array}$ & - & $\begin{array}{c}1,7 \\
\text { Milhões }\end{array}$ & $\begin{array}{c}\mathbf{1 , 2} \\
\text { Milhões }\end{array}$ & \multirow{2}{*}{848 Mil } & $\begin{array}{c}1,4 \\
\text { Milhões }\end{array}$ & 329 Mil & - \\
\hline
\end{tabular}

Fonte: Dados da pesquisa

No ano de 2014 a cooperativa teve seu maior crescimento da carteira de crédito e em 2015 alcançou a maior participação da pessoa jurídica na carteira, ao mesmo tempo em que teve seu maior resultado de exercício. Este último pode ser diretamente influenciado pela redução de provisão comparada com anos anteriores e a redução dos contratos em prejuízo.

Destaca-se na Tabela 5 o provisionamento de inadimplentes da carteira pessoa jurídica nos anos de 2012, 2013 e 2014, durante estes períodos apresentaram-se os maiores provisionamentos (5,3 $\mathrm{Mi} ; 6,9 \mathrm{Mi}$; e 6,8 Mi, respectivamente), o que coincide com períodos de retração na economia com o PIB em 0,90\%, 2,30\% e 0,10\% respectivamente, corrobora ainda com os achados de Bonizio e Silva (2018), que apontam uma diminuição do total em carteira de crédito e no resultado das operações de crédito nos anos de 2013 e 2014.

Os dados reforçam a necessidade de uma análise de crédito mais assertiva e um controle das liberações após sua negociação. Destes dois critérios o índice de inadimplência tende a reduzir bem como de prejuízo e aumenta-se as receitas. A contribuição dos créditos da pessoa jurídica para a construção do resultado é inegável.

Estes dados demonstram claramente a ineficiência e ineficácia da análise de crédito para a pessoa jurídica. Demonstrada principalmente devido ao alto número de inadimplência e provisionamento de risco devido a atrasos ou outros problemas.

\subsection{Proposta de ferramenta de análise de crédito amplo para pessoa jurídica}

Com o pleno conhecimento da contribuição da carteira pessoa jurídica para o resultado da instituição, bem como o impacto que a análise de crédito incompleta pode causar tanto na provisão quanto no prejuízo, e ainda as causas da inadimplência, buscou-se na literatura ferramentas de análise de crédito que possam tornar mais eficientes e eficaz o processo.

O ideal de uma operação de crédito é que no momento da negociação possa ser realizada as observações qualitativas e quantitativas necessárias para a análise, e possibilite a redução ou mitigação de riscos que a instituição não está disposta a assumir.

Atualmente a instituição possui para a análise de crédito pessoa jurídica uma análise superficial do balanço e DRE dos últimos 3 anos, análise do Rating fornecido pelo sistema com base no cadastro do cooperado, análise de endividamento por meio do relatório do Bacen e do SERASA, análise das garantias e informações dos sócios.

Segundo Gartner, Moreira, Galves (2009) é importante o especialista, no caso o analista de crédito, ter acesso a um método de análise da gestão de riscos corporativos, para poder ponderar esses itens. 
Com a ferramenta proposta neste artigo a cooperativa passará a ter uma análise da solvência da empresa por meio do termômetro de Kanitz (1974); análise dos riscos corporativos (operacional, estratégico, financeiro e perigos) de forma compilada a gerar um novo Rating geral da operação.

Com base na pesquisa bibliográfica, elaborou-se questões em tornos dos vários riscos que a empresa pode estar exposta, de acordo com os exemplos expostos na literatura adicionados as respostas dadas pelos gerentes de relacionamento durante coleta de dados. Chegou-se assim as perguntas que irão compor os questionários dos riscos operacionais, estratégicos, financeiros e os perigos.

Tabela 6 - Análise dos riscos operacionais

\begin{tabular}{|c|c|c|}
\hline Item & Descrição & Resposta \\
\hline 1 & Possui planejamento de riscos Operacionais? & 1 \\
\hline 2 & Teve alguma readequação nos processos internos nos últimos 5 anos? & 1 \\
\hline 3 & Possui algum programa de saúde para colaboradores? & 1 \\
\hline 4 & Possui prevenção a acidentes? & 1 \\
\hline 5 & Possui programa de capacitação para seus colaboradores? & 1 \\
\hline 6 & Possui boa disponibilidade de mão de obra? & 1 \\
\hline 7 & Possui logística bem definida de abastecimento a produção? & 1 \\
\hline 8 & Possui logística bem definida de abastecimento a clientes? & 1 \\
\hline 9 & Possui algum programa de atendimento e resolução de reclamações? & 1 \\
\hline 10 & A cultura organizacional é de alta performa-se? & 1 \\
\hline 11 & $\begin{array}{l}\text { Sua capacidade produtiva está sendo toda utilizada? (não possui } \\
\text { ociosidade) }\end{array}$ & 1 \\
\hline 12 & Possui relatórios confiáveis? & 1 \\
\hline 13 & Seu sistema de informação é eficiente e atualizado? & 1 \\
\hline 14 & Possui controle de estoque eficiente? & 1 \\
\hline 15 & Layout de produção é adequado? & 1 \\
\hline 16 & $\begin{array}{l}\text { Equipamentos utilizados são modernos, em bom estado, eficientes e } \\
\text { eficazes? }\end{array}$ & 1 \\
\hline 17 & Possui processos por problemas contratuais? & o \\
\hline 18 & Possui revisão periódica de seus contratos? & 1 \\
\hline 19 & Possui todas as certificações necessárias para funcionamento? & 1 \\
\hline 20 & Possui seguro patrimonial? & 1 \\
\hline 21 & Possui seguro de vida em grupo? & 1 \\
\hline 22 & Possui programa de prevenção e combate a fraudes internas? & 1 \\
\hline 23 & $\begin{array}{l}\text { Possui programa de manutenção preventiva de máquinas e } \\
\text { equipamentos? }\end{array}$ & 1 \\
\hline 24 & Possui planejamento tributário? & 1 \\
\hline \multirow[t]{2}{*}{25} & A empresa possui algum tipo de sonegação fiscal? & o \\
\hline & Pontuação Total & 23 \\
\hline
\end{tabular}

Nota: Têm-se o seguinte entendimento para as variáveis: $1=$ Sim; o = Não. Nos itens 17 e 25 a pontuação em caso de resposta afirmativa deve possuir pontuação -1.

Fonte: Dados da pesquisa

Com base nos exemplos de riscos operacionais citados em COSO (2007) em que diz que podemos considerar: tempo necessário para reparo de máquinas e equipamentos, índice de peças defeituosas, capacidade de demanda, segurança de empregados, logística. O gerente que negociar o 
crédito será o responsável em preencher as planilhas e deverá alterar apenas o campo de respostas das perguntas. Ao final, a planilha apresentará uma soma que enviará automaticamente para o campo resultado.

Em perguntas nas quais as respostas esperadas como ideias forem "não", e a empresa responder como "sim", deverá ser colocada na planilha como "-1" de modo a agravar o risco analisado em questão.

Tabela 7 - Análise dos riscos estratégicos

\begin{tabular}{|c|c|c|}
\hline $\begin{array}{l}\text { Ite } \\
\text { m }\end{array}$ & Descrição & Resposta \\
\hline 1 & A empresa possui planejamento estratégico? & 1 \\
\hline 2 & Existe acompanhamento do planejamento estratégico? & 1 \\
\hline 3 & Todos os setores têm conhecimento do planejamento estratégico? & 1 \\
\hline 4 & Conhece seus clientes? & 1 \\
\hline 5 & Conhece a concorrência? & 1 \\
\hline 6 & $\begin{array}{l}\text { Possui alguma vantagem em seu produto quanto ao do seu principal } \\
\text { concorrente? }\end{array}$ & 1 \\
\hline 7 & Possui acompanhamento do consumo do seu público alvo? & 1 \\
\hline 8 & Possui acompanhamento da sua atividade? & 1 \\
\hline 9 & Seus produtos possuem boa qualidade? & 1 \\
\hline 10 & Possui plano de marketing? & 1 \\
\hline 11 & Seu plano de marketing é adequado? & 1 \\
\hline 12 & Possui planos de expansão? & 1 \\
\hline 13 & Possui estudo de viabilidade para expansão de filiais? & 1 \\
\hline 14 & Possui plano de expansão de novos produtos? & 1 \\
\hline 15 & Possui estudo de viabilidade para novos produtos? & 1 \\
\hline 16 & Acompanha feiras e eventos do ramo em que atua? & 1 \\
\hline 17 & Acompanha as movimentações na sua área? & 1 \\
\hline 18 & Possui metas estabelecidas? & 1 \\
\hline 19 & As metas são claras? & 1 \\
\hline 20 & $\begin{array}{l}\text { As metas e o planejamento estratégico estão alinhados a missão e } \\
\text { visão? }\end{array}$ & 1 \\
\hline 21 & Possui aprimoramento constante de seus produtos/serviços? & 1 \\
\hline 22 & $\begin{array}{l}\text { Acompanha movimentação dos concorrentes (fusão, incorporação, } \\
\text { falência)? }\end{array}$ & 1 \\
\hline 23 & $\begin{array}{l}\text { Possui em sua carteira de clientes entidades de administração } \\
\text { pública? }\end{array}$ & o \\
\hline 24 & Seu faturamento está concentrado em um ou poucos clientes? & o \\
\hline 25 & Possui concentração de fornecedores? & o \\
\hline 26 & Pontuação Total & 22 \\
\hline
\end{tabular}

Nota: Têm-se o seguinte entendimento para as variáveis: 1 = Sim; o = Não. Nos itens 23, 24 e 25 a pontuação em caso de resposta afirmativa deve possuir pontuação -1.

Fonte: Dados da pesquisa

Os riscos estratégicos darão a possibilidade de uma análise qualitativa quanto à noção de estratégias de lançamentos de novos produtos, bem como expansão da marca por meio de filiais ou novas áreas de atuação. 
Da mesma forma como na análise de Riscos operacionais, para algumas perguntas a resposta ideal esperada é não, são elas as de números 23, 24 e 25. A partir do "não" como resposta, identificase a não existência de risco ou baixo risco quanto a concentração de clientes e fornecedores e o tipo de ambos.

Para elaborar a avaliação dos riscos financeiros utilizaram-se exemplos citados em COSO (2007) que relata o conhecimento, orçamento e projeção de fluxo de caixa, acompanhamento de variações no fluxo de caixa, aderência do fluxo de caixa, ausência de geração de caixa na atividade da empresa, acompanhamento do desempenho financeiro.

Segundo Ferma (2003) são exemplos de riscos que as empresas estão expostas: alavancagem financeira, contratos com risco cambial, ausência de proteção a variação do câmbio, baixa liquidez, oferta de crédito no mercado.

Tabela 8 - Análise dos riscos financeiros

\begin{tabular}{|c|c|c|}
\hline Item & Descrição & Resposta \\
\hline 1 & Possui orçamento e projeção de Fluxo de caixa para o exercício? & 1 \\
\hline 2 & Acompanha as variações de orçamento e projeção de fluxo de caixa? & 1 \\
\hline 3 & Esta aderente ao orçamento e fluxo de caixa (positivo, negativo, nivelado)? & 1 \\
\hline 4 & Empresa possui geração de caixa na atividade operacional? & 1 \\
\hline 5 & Possui controle e acompanhamento do desempenho financeiro? & 1 \\
\hline 6 & Empresa está com endividamento alavancado? & o \\
\hline 7 & Possui contratos de empréstimo com taxa cambial? & 1 \\
\hline 8 & Possui proteção a variação do câmbio? & 1 \\
\hline 9 & Possui índices de liquidez acima de 1 ? & 1 \\
\hline 10 & Possui disponibilidade de crédito no mercado? & 1 \\
\hline 11 & Relatórios financeiros são completos e exatos? & 1 \\
\hline 12 & Possui patrimônio capaz de liquidar suas obrigações em situações extremas? & 1 \\
\hline 13 & Possui reservas financeiras (de lucros, de capital, fundo de reservas)? & 1 \\
\hline 14 & $\begin{array}{l}\text { Possui acompanhamento de empréstimos sensíveis a variações econômicas e } \\
\text { políticas? }\end{array}$ & 1 \\
\hline 15 & Possíveis operações de câmbio são protegidas? & 1 \\
\hline 16 & Possui provisão de liquidações duvidosas? & 1 \\
\hline 17 & Possui sistema de cobrança de inadimplentes? & 1 \\
\hline 18 & Possui acompanhamento constante das políticas econômicas? & 1 \\
\hline 19 & Possui investimentos de alto risco? & $\mathrm{o}$ \\
\hline 20 & Possui seguro patrimonial? & 1 \\
\hline 21 & Possui sazonalidade na geração de caixa? & $\mathrm{O}$ \\
\hline 22 & Os custos, preços e margens estão adequados aos dos seus concorrentes? & 1 \\
\hline 23 & Possui planejamento para vieses extremos da economia? & 1 \\
\hline 24 & Possui programa de tratamento e combate a perdas? & 1 \\
\hline 25 & Possui controle de gastos operacionais? & 1 \\
\hline 26 & Pontuação Total & 22 \\
\hline
\end{tabular}

Nota: Têm-se o seguinte entendimento para as variáveis: $1=$ Sim; o = Não. Nos itens 6, 19 e 21 a pontuação em caso de resposta afirmativa deve possuir pontuação -1 .

Fonte: Dados da pesquisa 
Quanto ao percentual de compatibilidade com as respostas desejadas trabalha-se neste item também $77 \%$ em relação aos riscos que a instituição está disposta a correr. Essa margem ocorre por entender que o crédito pode estar destinado a correção destes pontos.

Segundo Ferma (2003) os perigos a que as organizações estão expostas são resultado de ações naturais, riscos de responsabilidade civil como incêndio ou contaminação do solo e/ou do lençol freático. Ainda segundo IBGC (2007) é importante prevenir qualquer eventualidade de responsabilidade civil.

Tabela 9 - Análise de perigos

\begin{tabular}{c|l|c}
\hline Item & \multicolumn{1}{|c|}{ Descrição } & Resposta \\
\hline 1 & Atividade da empresa pode causar danos ao meio ambiente? & o \\
\hline 2 & Atividade da empresa pode causar danos a comunidade? & o \\
\hline 3 & Possui plano de contenção a danos a terceiros ou ao meio ambiente? & 1 \\
\hline 4 & Está inserido em área de risco de desastres naturais? & o \\
\hline 5 & Possui plano de minimização de efeitos de desastres naturais? & 1 \\
\hline 6 & Possui algum tipo de seguro contra desastres naturais? & 1 \\
\hline 7 & Possui algum tipo de seguro de responsabilidade civil? & 1 \\
\hline 8 & Possui plano de reaproveitamento e/ou tratamento de resíduos? & 1 \\
\hline 9 & Possui plano de prevenção e/ou combate a incêndios? & $\mathbf{6}$ \\
\hline $\mathbf{1 0}$ & Pontuação total & \\
\hline
\end{tabular}

Nota: Têm-se o seguinte entendimento para as variáveis: 1 = Sim; o = Não. Nos itens 6, 19 e 21 a pontuação em caso de resposta afirmativa deve possuir pontuação -1.

Fonte: Dados da pesquisa

Os questionamentos levantados na Tabela 9 que representam os perigos foram tomados com base na área de atuação da instituição estudada, no caso, Vale do Itajaí/SC. As questões tendem a descrever os eventos naturais pelos quais a empresa está exposta nesta região e podem ser adaptados com o risco da região, na qual será aplicado.

A ferramenta sugerida tem por objetivo a análise qualitativa da gestão e quantitativa conforme mencionado. Após a análise com base nos dados coletados pelo gerente de relacionamento durante visita de conhecimento da empresa e de suas necessidades, ele deverá preencher a análise quantitativa da empresa por meio das informações que possui no seu sistema.

\begin{tabular}{|c|c|}
\hline Descrição & Valor (RS) \\
\hline Ativo Circulante & $17.351 .293,00$ \\
\hline \multicolumn{2}{|l|}{ Ativo Realizável a Longo Prazo } \\
\hline Estoques & $10.660 .499,00$ \\
\hline Ativo Total & $27.845 .956,00$ \\
\hline Passivo Circulante & $8.267 .384,00$ \\
\hline Passivo Realizável a Longo Prazo & $8.603 .729,00$ \\
\hline Patrimônio Líquido & $10.974 .843,00$ \\
\hline Lucro Líquido & $1.530 .990,00$ \\
\hline Pontuação & 2 \\
\hline
\end{tabular}
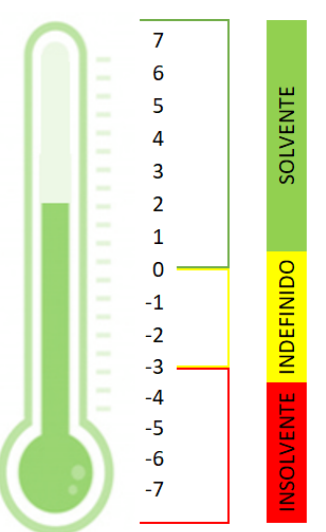

Figura 5: Termômetro de insolvência de Kanitz

Fonte: Dados da pesquisa 
Atualmente a instituição possui uma análise superficial dos índices de liquidez, rentabilidade do ativo e grau de alavancagem. Com a introdução do termômetro de Kanitz na ferramenta, ficará mais fácil para o gerente que negocia a operação entender a real situação da empresa por meio destes índices.

Por meio do termômetro de insolvência pode-se ter um grau de assertividade maior quanto a adimplência ou inadimplência futura da empresa tomadora, com uma agilidade e facilidade na interpretação dos dados.

Junto a estas novas ferramentas de análise somaram as ferramentas já existentes, chegou-se ao resultado da análise. A planilha de resultado importará automaticamente cada análise individual, de maneira a reproduzir um resultado total.

A Tabela 10 demonstra uma análise de um cliente pessoa jurídica com seu cadastro sem qualquer tipo de impeditivo no cadastro dos sócios ou da empresa, atendimento total da análise de riscos e perigos corporativos, situação de solvente e garantia real em 100\% do valor da operação.

A análise pontuou a operação próximo a sua pontuação máxima possível de 300 pontos, portanto a operação poderia ser liberada devido ao baixo risco e garantia adequada a operação.

Tabela 10: Causas da inadimplência dos cooperados pessoa jurídica

\begin{tabular}{l|c}
\hline \multicolumn{1}{c|}{$\quad$ Análise ampla } & Pontuação \\
\hline Riscos operacionais & 23 \\
\hline Riscos estratégicos & 22 \\
\hline Riscos financeiros & 22 \\
\hline Perigos & 6 \\
\hline Rating Sócios & 30 \\
\hline Termômetro de insolvência & 2 \\
\hline Rating & 30 \\
\hline Serasa & 30 \\
\hline Bacen & 30 \\
\hline Garantias & 100 \\
\hline Pontuação Total & 295 \\
\hline
\end{tabular}

Nota: Têm-se o seguinte entendimento para as possibilidades de resultado: Abaixo de 94 pontos = Operação não recomendada, alto risco; Entre 95 e 166 pontos = Operação recomendada com ressalvas, rever taxas e garantias; Acima de 167 pontos = Operação recomendada devido baixo risco.

Fonte: Dados da pesquisa

Com a introdução desta nova ferramenta, a instituição poderá analisar tanto aspecto de qualidade quanto a capacidade do tomador em manter a adimplência em curto, médio e longo prazo. Ela ganhará ainda em eficiência e agilidade, uma vez que tanto analista quanto o gerente terão acesso às mesmas informações e parâmetros de análise.

O objetivo final da ferramenta é extinguir a falta de análise dos riscos causadoras da inadimplência e prejuízo, possibilita-se a instituição majorar seus resultados e gerar maior atratividade e valor agregado a seus cooperados. 


\section{Considerações Finais}

A análise de riscos na concessão de crédito para pessoa jurídica e sua eficiência leva os diretores das instituições de crédito cooperativistas a uma reflexão do resultado do exercício de cada ano.

Em busca de demonstrar as atuais ferramentas de análise de risco na concessão de créditos adotados pela cooperativa pesquisada, evidenciou-se na ferramenta propostas os itens já utilizados.

Quanto a apresentação dos dados da carteira do crédito concedido pela instituição financeira cooperativa e ainda os fatores da inadimplência ficaram evidenciado que a participação da carteira PJ é atualmente de $69 \%$ da carteira geral e os seus fatores de inadimplência são ocasionados devido a um mau gerenciamento de riscos corporativos das empresas.

Ao comparar a mutação do nível de risco em períodos de crescimento da economia e de retração e qual seu impacto sobre a inadimplência e prejuízo, observou-se que o PIB teve retração, o que afetou a inadimplência e fez com que os níveis de provisionamento de devedores duvidosos aumentassem.

Para desenvolver a ferramenta de análise de crédito ampla, a qual permite avaliar a gestão dos riscos corporativos dos tomadores de crédito, foi proposto à instituição uma ferramenta que agregasse os riscos corporativos em que a empresa tomadora está exposta, mais o termômetro de insolvência de Kanitz e além disso manteve-se as ferramentas já utilizadas ao integra-las nesta nova ferramenta.

Nota-se que atualmente a análise de crédito para pessoa jurídica apresenta-se ineficiente e ineficaz. Tais instituições de crédito apresentam grandes índices de inadimplência. Atualmente a participação da pessoa jurídica na carteira de crédito é superior a pessoa física, situação que exige uma análise de crédito mais criteriosa e qualificada, frente a isso é fundamental uma ferramenta de análise ampla de crédito.

Recomenda-se e propõem-se novas pesquisas na área, mais especificamente quanto a análise de crédito para pessoa física, que possam apresentar novas formas de análise de crédito ou então novas ferramentas para a análise de crédito da pessoa física para que se possa ter instituições mais fortalecidas, um sistema financeiro de alta performance e cooperativas seguras.

\section{Referências}

BACEN (2016). Resolução $N^{\circ}$ 2.390, de 22/05/1997 do Banco Central do Brasil. Determina às instituições que especifica a prestação ao Banco Central do Brasil de informações sobre clientes, objetivando a implementação do sistema Central de Risco de Crédito. Recuperado de www.bcb.gov.br/pre/normativos/busca/downloadNormativo.asp?arquivo=/Lists/Normativos/Attach ments/45607/Res_2390_v1_O.pdf.

BACEN (2016). Resolução N 2.682, de 22/12/1999 do Banco Central do Brasil. Dispõe sobre critérios de classificação das operações de crédito e regras para constituição de provisão para créditos de liquidação duvidosa. Recuperado de www.bcb.gov.br/pre/normativos/res/1999/pdf/res_2682_v2_L.pdf.

B3 (2015). Política de gestão de riscos corporativos. Recuperado de ri.bmfbovespa.com.br/ptb/2494/Poltica\%20de\%20Gesto\%20de\%20Riscos\%20Corporativos_24092 015.pdf.

Brasil (1971). Lei 5.764/71. Recuperado de http://www.planalto.gov.br/ccivil_03/leis/L5764.htm 
Coimbra, F. C. (2011). Estrutura de governança corporativa e gestão de riscos: um estudo de caso no setor financeiro. Tese de Doutorado em Administração. São Paulo: USP

COSO. (2007). Gerenciamento de riscos corporativos. Recuperado de www.coso.org/documents/COSO_ERM_ExecutiveSummary_Portuguese.pdf.

Etges, A. P. B. S., Souza, J. S. (2015). Estudo de campo sobre gestão de riscos corporativos em empresas participantes de um parque científico e tecnológico. Recuperado de: incubadora.periodicos.ufsc.br/index.php/IJKEM/article/download/3286/4069.

Ferma. (2003). Norma de gestão de risco. Recuperado de agenciabrasil.ebc.com.br/economia/noticia/2016-04/desemprego-no-brasil-sobe-para-102-revelapesquisa-do-ibge.

Franco, D. S. (2018). Gestão do Crédito pelos órgãos de governança sob enfoque da Transparência: Estudo de Caso de uma Cooperativa de Crédito. 2018, 110 f. Dissertação. (Mestrado em Agronegócio) - Faculdade de Agronomia e Medicina Veterinária, Universidade de Brasília. Brasília.

Gartner, I. R.; Moreira, T. B.S.; Galves, H. M. (2009). Análise do risco setorial como instrumento de controle gerencial em instituições financeiras. São Paulo: RAM, V 10, 2009. Recuperado em 11 novembro, 2016. www.redalyc.org/pdf/1954/195415633006.pdf.

Heinzelmann, M.R.; Souza, S. (2009). Associativismo, uma história de sucesso. Joinville: Univille. IBGC - Instituto Brasileiro de Governança Corporativa (2016). Guia de orientação para gerenciamento de riscos corporativos. 2007. Recuperado de http://www.ibgc.org.br/userfiles/3.pdf.

Jacomossi, F. A., Sant, C., Reif, E., \& Fernandes, F. C. (2016). Gestão do risco estratégico em instituições bancárias: uma análise no período pós-crise subprime. Revista Grifos, 24(38/39), 113-142.

Kanitz, S. C. (1974). Como prever falência de empresas. Revista EXAME, 95-102.

Leite, P. H. Da C.; Alves, C. A.de M.; Filho, C. A.P. M. (2016). Gestão de risco operacional em uma instituição financeira pública que atua no Brasil: Um estudo de Caso. Rio de Janeiro. 2010. Recuperado em 27 outubro, 2016, de, www.epublicacoes.uerj.br/index.php/rcmccuerj/article/view/5498.

Meinen, Ê.; Port, M. (2012). O Cooperativismo de crédito ontem, hoje e amanhã. Brasília: Confebras.

Menezes, N. M. L. (2016) Gerenciamento de riscos de empresas não financeiras: Exigência e necessidade. Rio de Janeiro, 2012. Recuperado de http://modelosfinanceiros.com.br/sitefgr/assets/documentos/gerenciamento_de_risco_de_empresas _nao_financeiras.pdf.

Molyneux, P. (2018). Developments in Banking Research and Areas for Future Study. International Journal of the Economics of Business, 25(1), 167-179.

Önder, S.; Ergin, H. (2012). Determiners of enterprise risk management applications In Turkey: An Empirical Study With Logistic Regression Model On The Companies Included In ISE (Istanbul Stock Exchange). Istanbul: BEH, 7, 2012.

Pedote, C. F. S. (2016). Análise e gerenciamento de risco, gestão de riscos operacionais em instituições financeiras. São Paulo, 2002. Recuperado em 28 outubro, 2016, de, bibliotecadigital.fgv.br/dspace/bitstream/handle/10438/4919/1200200870.pdf?sequenc.

Pinho, D. B.; Palhares, V. M. A. (2010). O cooperativismo de crédito no Brasil do Século XX ao Século XXI. Brasília: Confebras. 
Pinto, E. S. S. (2016). Gestão de riscos corporativos em uma empresa de telecomunicações. Pedro Leopoldo, MG, 2012. Recuperado de www.fpl.edu.br/2013/media/pdfs/mestrado/dissertacoes_2012/dissertacao_eduardo_sardinha_2012.p df.

Sá, J. M. D. C., Silva, I. R. R., da Silva, R. G., Souto, L. G. A., \& Silva, P. G. S. (2018). Análise de Crédito Utilizando uma Abordagem de Mineração de Dados. Revista de Engenharia e Pesquisa Aplicada, 3(3).

Santos, J. O. (2012) Análise de crédito. 5 ed. São Paulo: Atlas.

Santos, L. S. Z., Bressan, V. G. F., Braga, M. J., \& Guerra, C. M. A. (2018). Gerenciamento de resultados e eficiência: um estudo nas cooperativas de crédito filiadas ao sistema Unicred. Revista de Gestão e Organizações Cooperativas, 5(10), 19-32.

Scarpel, R. A., \& Milioni, A. Z. (2002). Utilização conjunta de modelagem econométrica e otimização em decisões de concessão de crédito. Pesquisa Operacional, 22(1), 61-72.

Schrickel, W. K. (1994). Análise de crédito, concessão e gerência de empréstimos. São Paulo: Atlas.

Sicsú, J. (2018). A economia da depressão está de volta.

Silva, J. P. (2008). Gestão de análise de risco de crédito. 6 ed. São Paulo: Atlas.

SPC. (2016). Indicadores de inadimplência de pessoas jurídicas SPC Brasil e CNDL. 2016. Recuperado de www.spcbrasil.org.br/wpimprensa/wp-content/uploads/2016/07/An\%25 $3 \% 25 A_{1}$ liseInadimpl\%25C3\%25AAncia-PJ-_-junho-2016.pdf+\&cd=1\&hl=pt-BR\&ct=clnk\&gl=br.

Tavares, R. F. (1988). Crédito e cobrança. São Paulo: Atlas.

YERKAUFER, M. L.; RENGEL, R. 